

\title{
MEMORIA FOTOGRÁFICA
}

\author{
BELLAVISTA
}

WORKSHOP FAAF BELLAVISTA 2017, es la cuarta versión del programa FAAF, Fotografía de Arquitectura y viceversa' realizado en el Barrio Bellavista de la comuna de Tomé, entre los días 26 y 28 de mayo del 2017, asociado al Plan de Gestión Social "Tejiendo Nuestra Historia" del Programa de Recuperación de Barrios "Quiero Mi Barrio" Bellavista del Ministerio de Vivienda y Urbanismo (MINVU) y la llustre Municipalidad de Tomé de la Región del Biobío. El taller estuvo dirigido a vecinos/as mayores de 18 años, moradores o trabajadores de dicho barrio, interesados en fotografiar su propio territorio y visibilizar colectivamente un nuevo paisaje. La experiencia tuvo como resultado la creación de una serie inédita de 10 tarjetas postales (dípticos). Este clásico formato que promueve la circulación de imágenes icónicas de arquitectura y paisaje de un lugar determinado, hoy es revisitado y transformado en soporte de una propuesta fotográfica contemporánea².

El barrio surge a partir de la creación de la Fábrica de Paños Bellavista-Tomé, propiedad del empresario Guillermo Délano Ferguson, construida en 1865. La emblemática empresa, que llegó a convertirse en una de las principales industrias textiles de Latinoamérica, actualmente se enfrenta a un futuro incierto luego de bajar considerablemente su producción. Hoy la fábrica es considerada un patrimonio histórico de nuestra arquitectura industrial y para los Tomecinos es parte fundamental de su identidad cultural. Mientras tanto los vecinos del barrio, que han vivido y convivido con la fábrica, se mantienen preocupados por el futuro de su comunidad, por sus actividades productivas y por el mejoramiento de su entorno inmediato.

DOI: https://doi.org/10.22320/07196466.2017.35.051.08

[1] FAAF, Fotografia de Arquitectura y viceversa, es un Workshop de teoría y creación fotográfica que intenta ampliar la mirada sobre lo que se conoce y entiende sobre fotografía de arquitectura, profundizando en la arquitectura de la fotografía. El Workshop se plantea desde la visión critica de la arquitectura y su territorio a partir de la producción de un discurso relatado fotográficamente como lenguaje contemporáneo y con la aspiración de aportar a la memoria y patrimonio local. Así, se intenta crear un entorno pedagógico que permita la construcción de una fotografía de arquitectura y que esta, a su vez, configure un discurso crítico, en cuanto lenguaje no verbal, detonado siempre por una experiencia significativa con el lugar/objeto de estudio. Ver: www.faaf.cl

[2] EQUIPO: Ignacio Bisbal, Hernán Ascuí y Nicolás Sáez (Talleristas); Marcos Espinoza (Asistente diagramación e impresión); Yasmina Villa (Producción Audiovisual); Lorena Gómez (Banquetería). PARTICIPANTES: José González Francisco Matamala, Erika Aguayo, Sofia Anabalón, Iliam Delgado, Hilda Basoalto, Wladiz Bustos, Jorge Méndez y Erwin Sanhueza. 
Los trabajos realizados en este breve pero intenso periodo de creación fotográfica indagaron en experiencias íntimas, reconociendo por sobre todo a las personas y oficios que han permanecido desde los orígenes del barrio. Cada autor fue encontrando los síntomas visuales de la valorización de lo propio y lo cotidiano. El paisaje se nutre esta vez de la "intimidad de barrio", como atmósfera relatada visualmente desde una particular memoria colectiva. Bajo el concepto de "Bella Vista"3, ampliado lo más posible para superar la acepción inmediata que surge en nuestro imaginario personal al valorar estéticamente un paisaje, cada autor quiso visibilizar un retrato-relato que creyó relevante para constituirse como un nuevo paisaje. Estas postales nos cuentan algo más sobre el Barrio Bellavista, imágenes que se incorporan a la extensa memoria visual archivada y reconocida por la comunidad. La imagen es memoria, archivo y discurso presente.

La serie comienza con el trabajo de José González, quien decide fotografiar a su padre en un íntimo episodio que marcó la historia familiar. José fotodocumenta con una puesta en escena sutil un instante contemplativo y cargado de emoción, todo detonado por un breve y bello texto en primera persona. Hilda Basoalto, de manera similar, retrata la relación de dos hermanas, ambas tías de Hilda, que llevan "toda una vida juntas". Surge la mirada de la autora que valora aquellas actividades en compañía. Actos simples y cotidianos dentro de una atmósfera doméstica cargadas de elementales altares de recuerdo y credo. Son retratos de lo conocido y admirado, puesta en escena activada por la memoria.
Wladiz Bustos nos quiso contar sobre doña María Benítez Rodríguez que forma parte de una familia trabajadora de la fábrica de paños. Doña María aún mantiene vivo el oficio de tejedora. Wladiz hizo el simple ejercicio de visitarla y conversar con ella. Luego de retratarla en el umbral de su casa pudo descubrir su intimidad doméstica logrando capturarla y profundizar su relato visual. Wladiz narra, a través de tres fotografías, la relación entre el espacio público y el privado, entendiendo este último como un tesoro a descubrir. Erwin Sanhueza también quiso revalorar un oficio, el del último zapatero del barrio. Erwin visitó a Magdalena del Carmen Fernández, viuda de Isaías Fernández, fabricante de zapatos de Bellavista. Un retrato directo con el clásico gesto visibilizador del familiar fallecido y otro sobre las hormas de madera, que aún permanecen en su lugar. Erwin sintetiza con un díptico fotográfico la frase "mi tranquilidad", una suerte de diacronía dramática que lleva un doble luto: el del ser querido y el de su oficio desaparecido. Sofía Anabalón conoció a "Nonino", comerciante del barrio. Ella realza el preciso instante cuando Nonino interactúa con sus clientes. La acción de limpiar y vender el pescado activa la atmósfera de su pequeño local con colores, brillos y movimentos rápidos. Sofía, con su lente luminoso de $50 \mathrm{~mm}$, logra congelar la escena pictóricamente. Lo háptico esta vez pareciera ser protagonista en el lenguaje visual. Iliam Delgado, por su parte, escogió a don Miguel Ramis "el Cuto", vecino que recorre diariamente el barrio en bicicleta. Iliam lo visita y conoce la historia personal que impulsó a este vecino a optar por este medio de transporte. La fotografía registra síntomas que revelan aquel relato. Francisco Matamala des-

[3] Bello, lla. Del lat. bellus "bonito". 1. adj. Que, por la perfección de sus formas, complace a la vista o al oído y, por ext., al espíritu. 2. adj. Bueno, excelente. (RAE) / Vista. Del lat. tardio *vista, der. del lat. vidēre 'ver'.1. f. Sentido corporal con que los ojos perciben algo mediante la acción de la luz. 2. f. Conjunto de los órganos de la visión. 3. f. visión (ll acción de ver).4. f. Aspecto o disposición de las cosas que se ven. 5. f. Panorama que se ofrece al espectador desde un punto. U. t. en pl. con el mismo significado que en sing. 6 . f. Representación pictórica o fotográfica de un lugar o monumento. 7. f. Conocimiento claro de las cosas.8. f. Intento o propósito.9. f. Parte de una cosa que no se oculta a la vista. 10. f. Mirada superficial o ligera.11. f. Sagacidad para descubrir algo que otros no ven. 12. $f$. Der. Comparecencia ante un juez o tribunal en la que las partes exponen los fundamentos de sus respectivas pretensiones.13. $f$. desus. visera (\|l parte del yelmo).14. f. pl. Concurrencia de dos o más personas que se ven para fin determinado.15. f. pl. Regalos que reciprocamente se hacen los novios.16. f. pl. Ventana, puerta u otra abertura en los edificios, por donde entra la luz para ver.17. f. pl. Galerías, ventanas u otros huecos de pared, por donde desde un edificio se ve lo exterior.18. m. Empleado de aduanas a cuyo cargo está el control de las mercancías (RAE). 
cubre en el reflejo del estero que recorre el barrio dos elementos que han transformado el paisaje lejano: los pinos y eucaliptos de las plantaciones forestales que cubren los cerros del este; y las torres residenciales que han surgido delante del horizonte abierto del oeste. Fotogénicas bellas vistas del paisaje interior que nos hablan, políticamente, del asedio especulativo del mercado. A Erika Aguayo le impresiona "la casa del Toro" ubicada cerca del acceso principal del Barrio Bellavista; particular escultura de un toro instalada en un antejardín y que da la bienvenida a los vecinos y visitantes del barrio. Erika lleva a cabo dos retratos frontales: a la obra y al escultor. Agrega un breve texto transcrito de la conversación con este último. Erika retrata y relata este nuevo paisaje popular que ya es parte de este barrio histórico. Jorge Méndez decide captar el exterior de la fábrica de paños, pero desde su presencia en el espacio íntimo y doméstico del barrio. A lo lejos y fragmentada se divisa la fábrica al abrir una ventana o salir al patio. Estas fotografías recrean dichas vistas atemporalmente, ayudadas por un preciso relato extraído del libro "Bellavista. Memoria oral de un pueblo industrial ${ }^{\prime \prime 4}$.

Al finalizar y de manera colectiva, hemos puesto en diálogo dos imágenes de archivo que muestran el interior de la Fábrica de Paños. Una en blanco y negro perteneciente a la época de su pleno funcionamiento y la otra de 2013, último año en el que fue abierta al público con motivo del Día Nacional del Patrimonio. La primera es anónima y no posee mayor información ${ }^{5}$. La segunda fue tomada por José González que logró introducir el lente de su cámara a través de pequeñas perforaciones de una puerta que se mantenía cerrada. Ambas imágenes revelan y ocultan algo de esta fábrica. La fotografía visibiliza e invisibiliza simultáneamente. Dominar el poder de la imagen fotográfica está en saber leer por sobre todo, lo que no se muestra. La imagen expuesta es un hecho político.

Nicolás Sáez Gutiérrez ${ }^{6}$

[4] Pérez Lizana, Sebastián; Becker, Eduardo; Saavedra, Maura y Saldias, Eduardo. Bellavista, Memoria oral de un pueblo Industrial [en línea]. Concepción: Edición independiente, 2010. [Consultado 15 junio2017]. Disponible en: http://textileschile.cl/archivos_media/ memoria-oral-de-un-pueblo-industrial.pdf

[5] La fotografía posee buena resolución y ha sido catalogada como "fotografía antigua de Bellavista" en taringa.net, una comunidad virtual de descarga gratuita de información.

[6] Académico Departamento de Diseño y Teoría de la Arquitectura, Universidad del Bío-Bío, Concepción, Chile.nsaez@ubiobio.cl 
JOSÉ
GONZALEZ
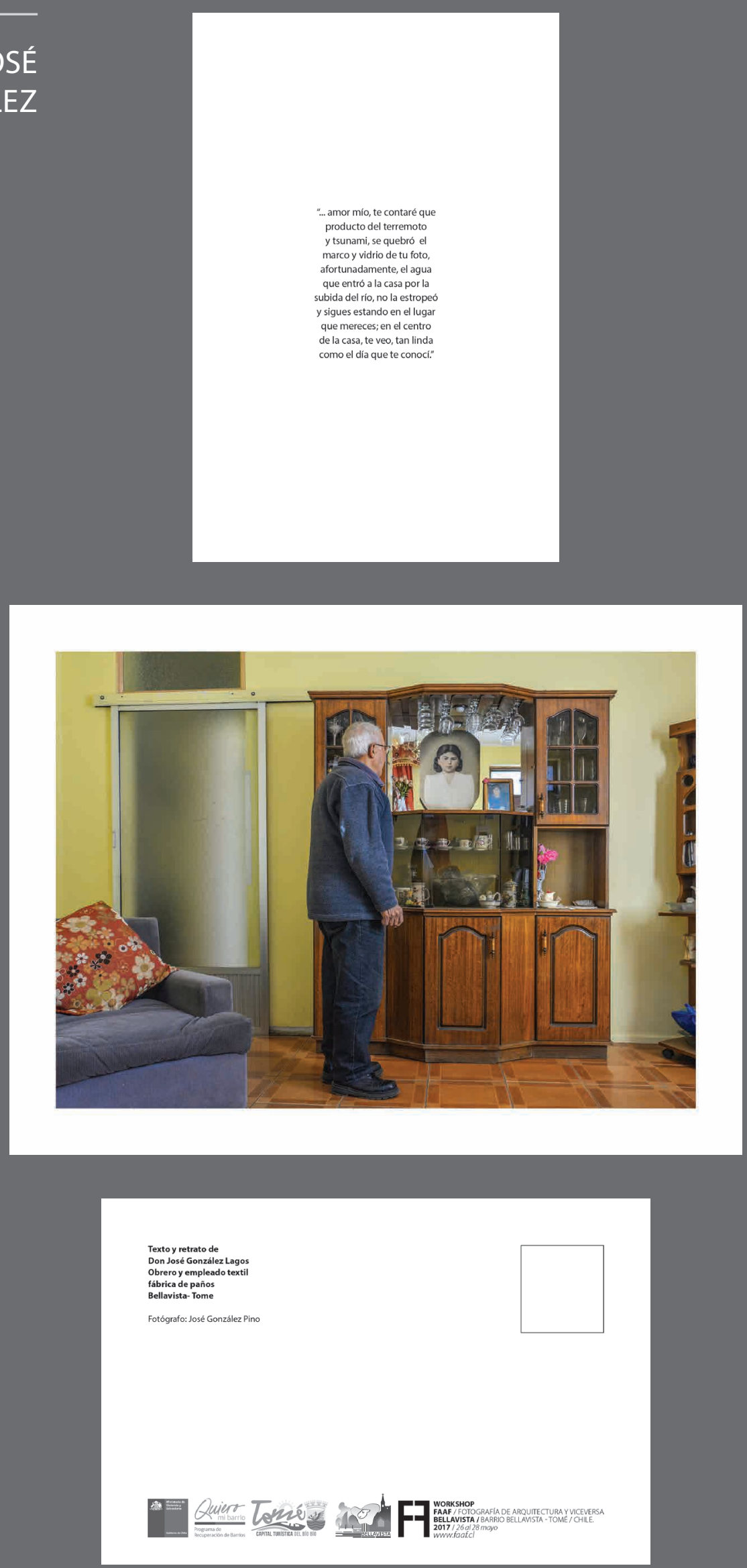


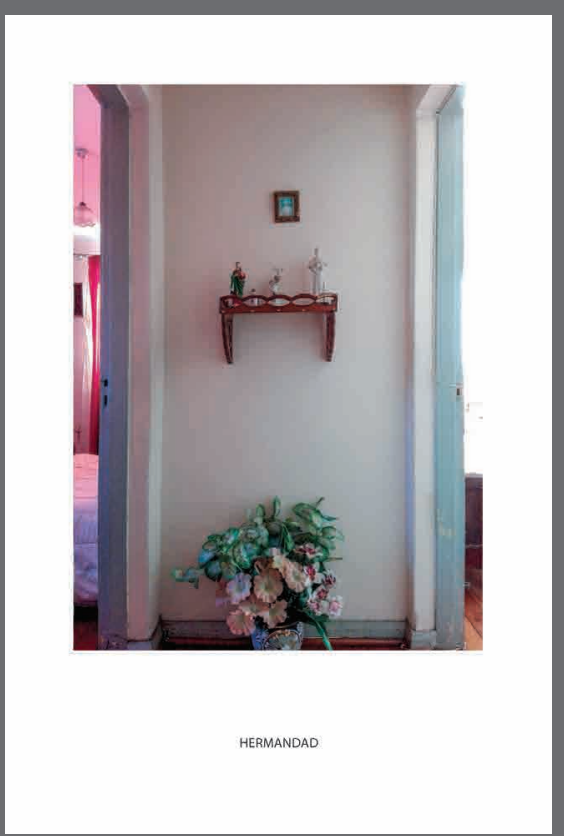

HILDA

BASOALTO
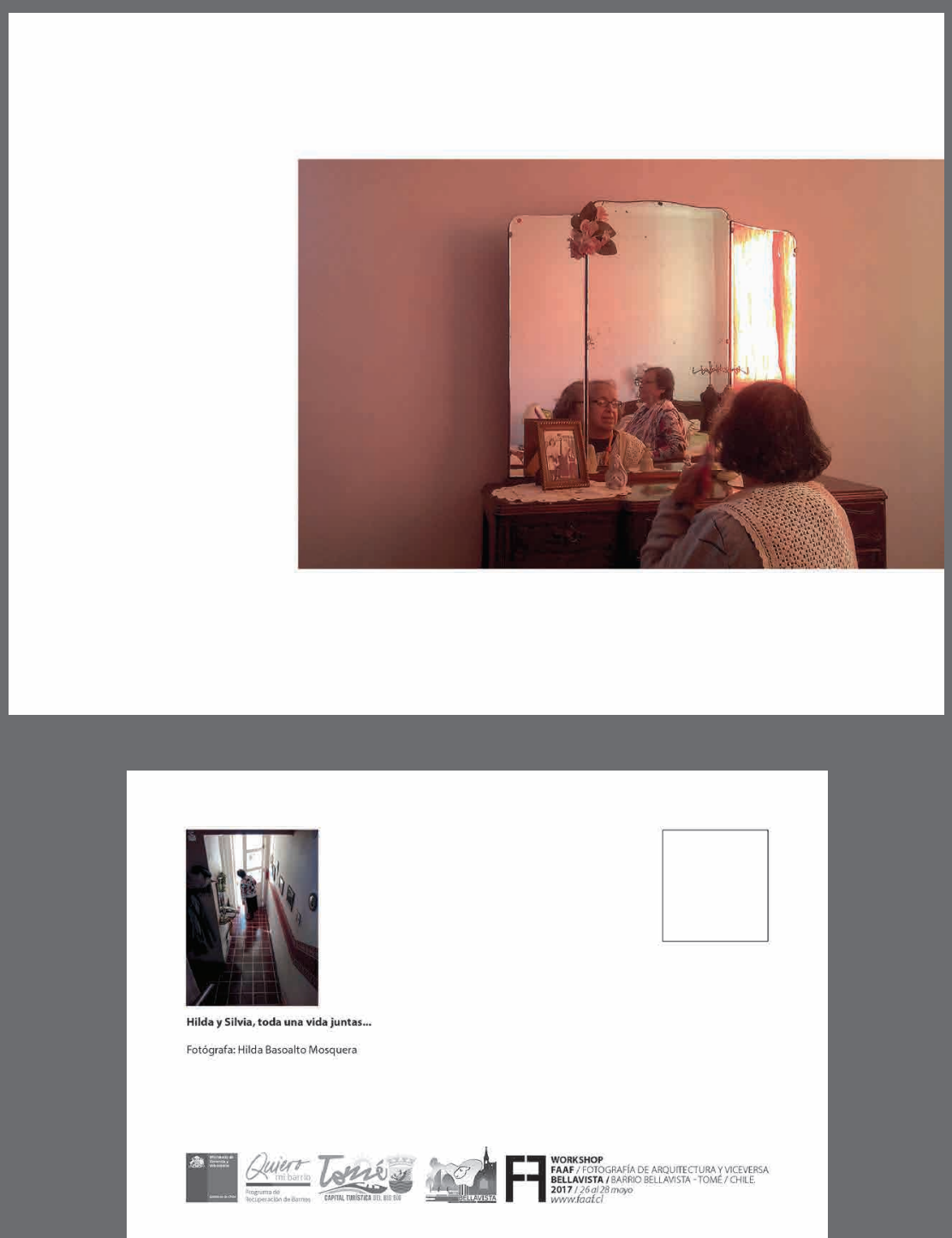
WLADIZ BUSTOS
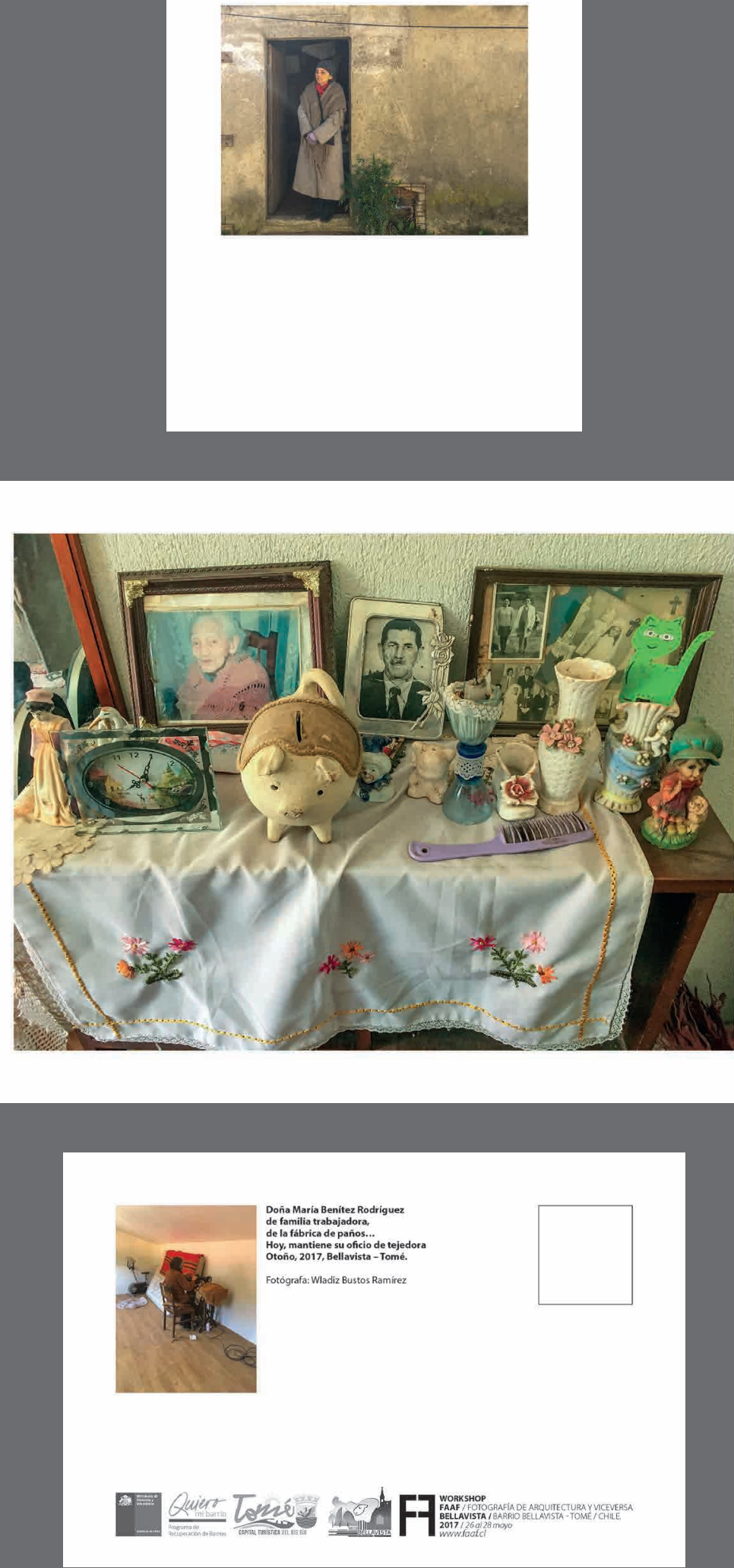


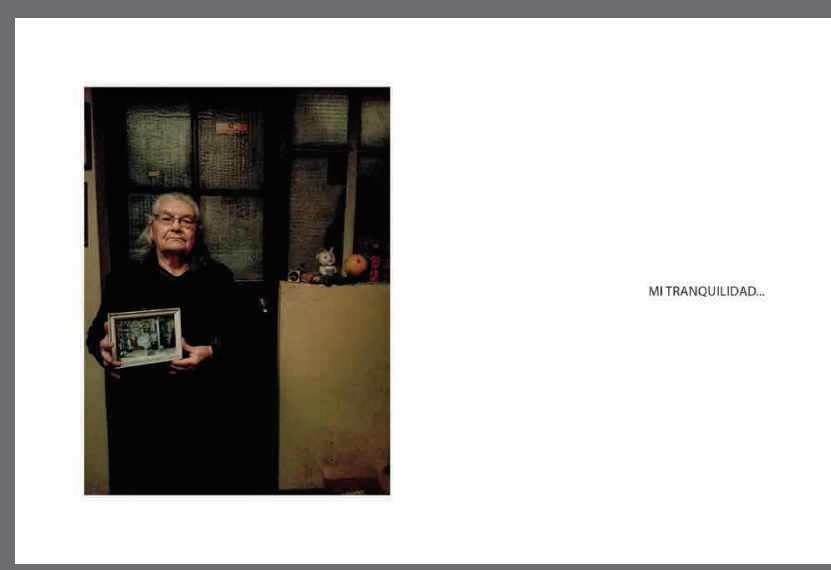

ERWIN

SANHUEZA

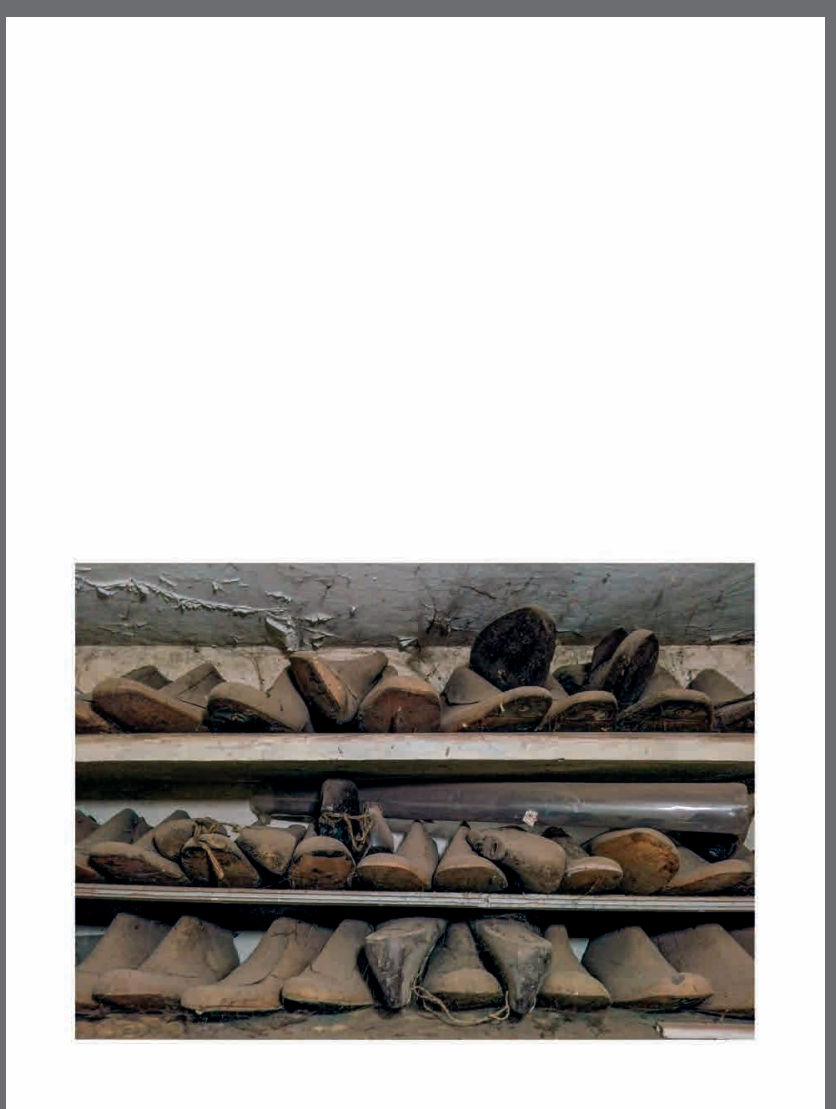

Magdalena del Carmen Fernández Escobar
Viuda del fabricante de zapatos de esellavista

Viuda del fabricante de zapatos de Bellerist

Fotógrafo: Erwin Sanhueza Galind

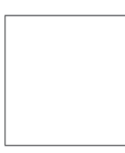

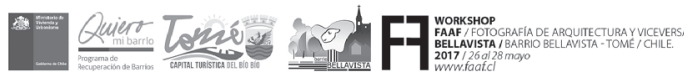




\section{SOFÍA ANABALÓN}
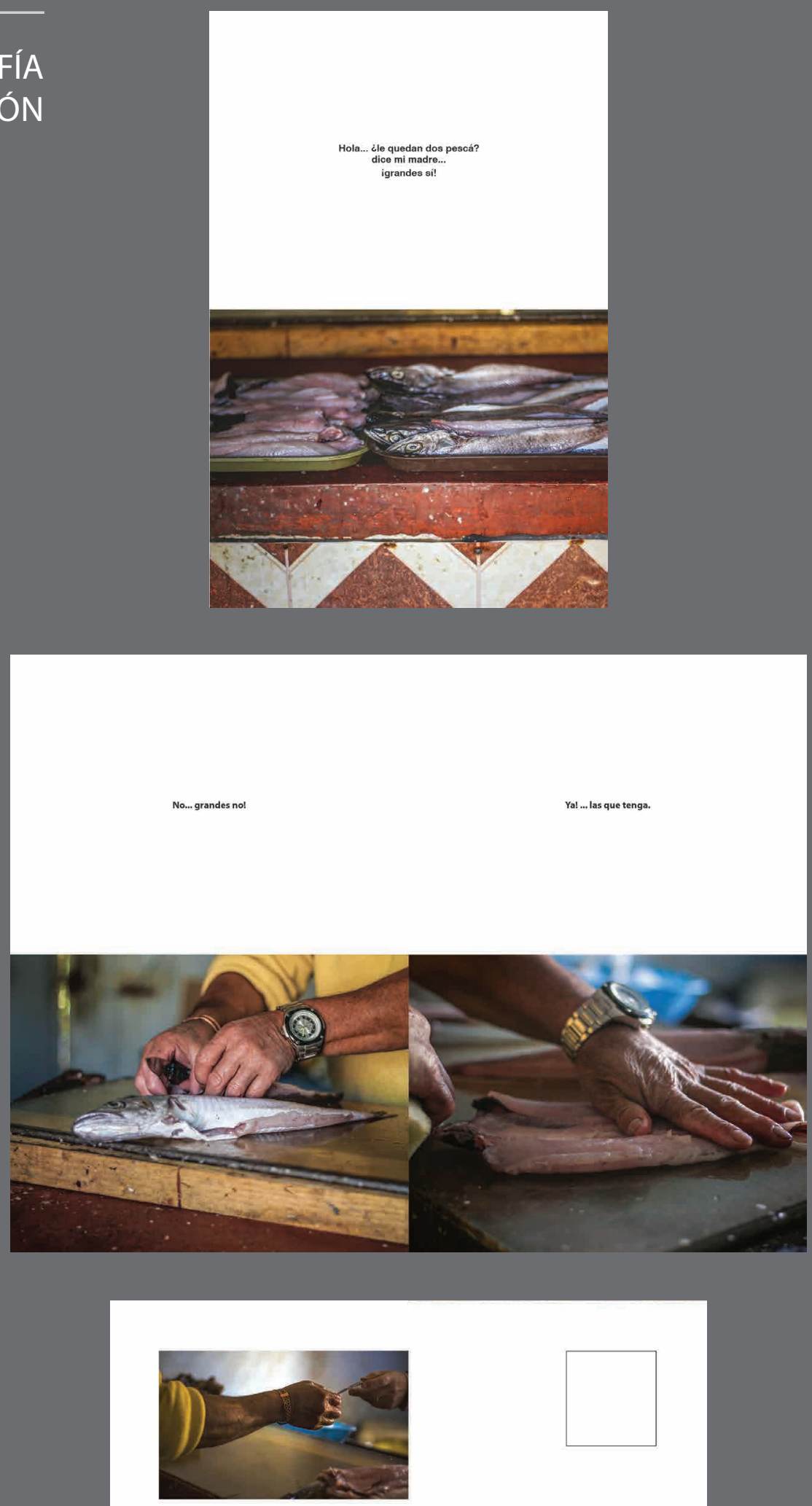

Masonino 30 años vendiendo pescado

en barrii Bellovista- Tom

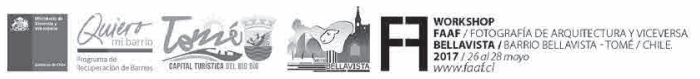




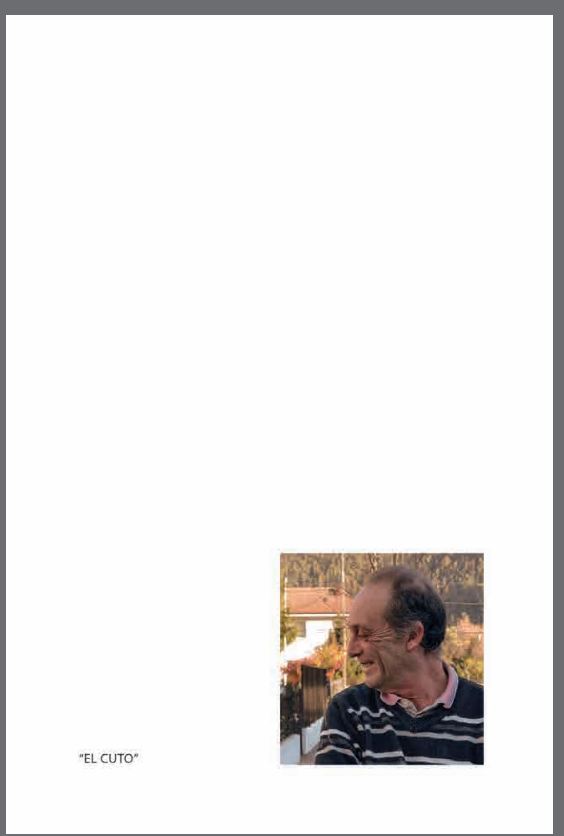

\section{ILIAM \\ DELGADO}

"En el 2004 tuve un accidente, Un choque
eutomovilistico. Estoy lleno de fierros en la

cadera. Tengo problemas al ciático. Me operal

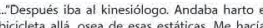

andar en bicicleta como ejercicio, como terapia".
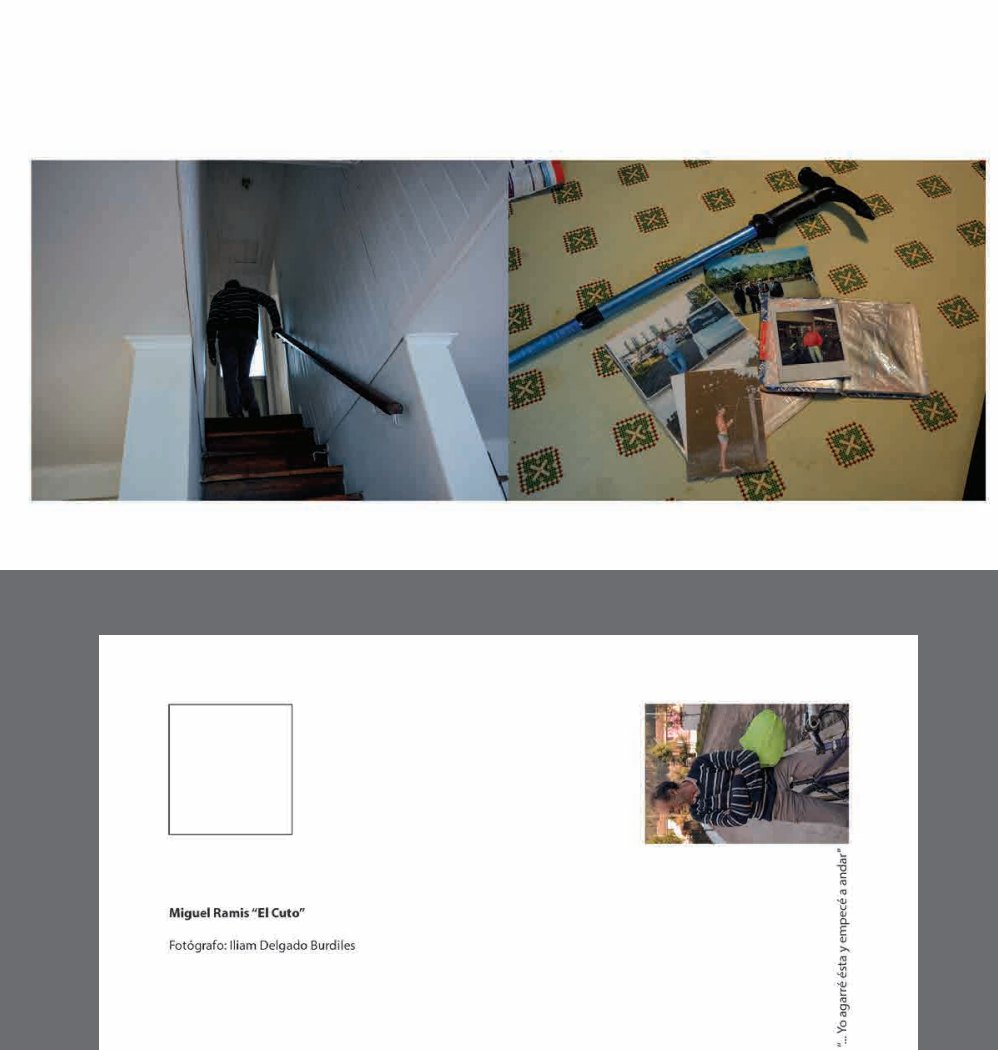

Miguel Ramis "El Cuto"

Fotógrafo: liam Delgado Burdiles

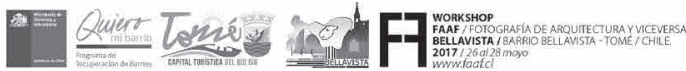


FRANCISCO MATAMALA
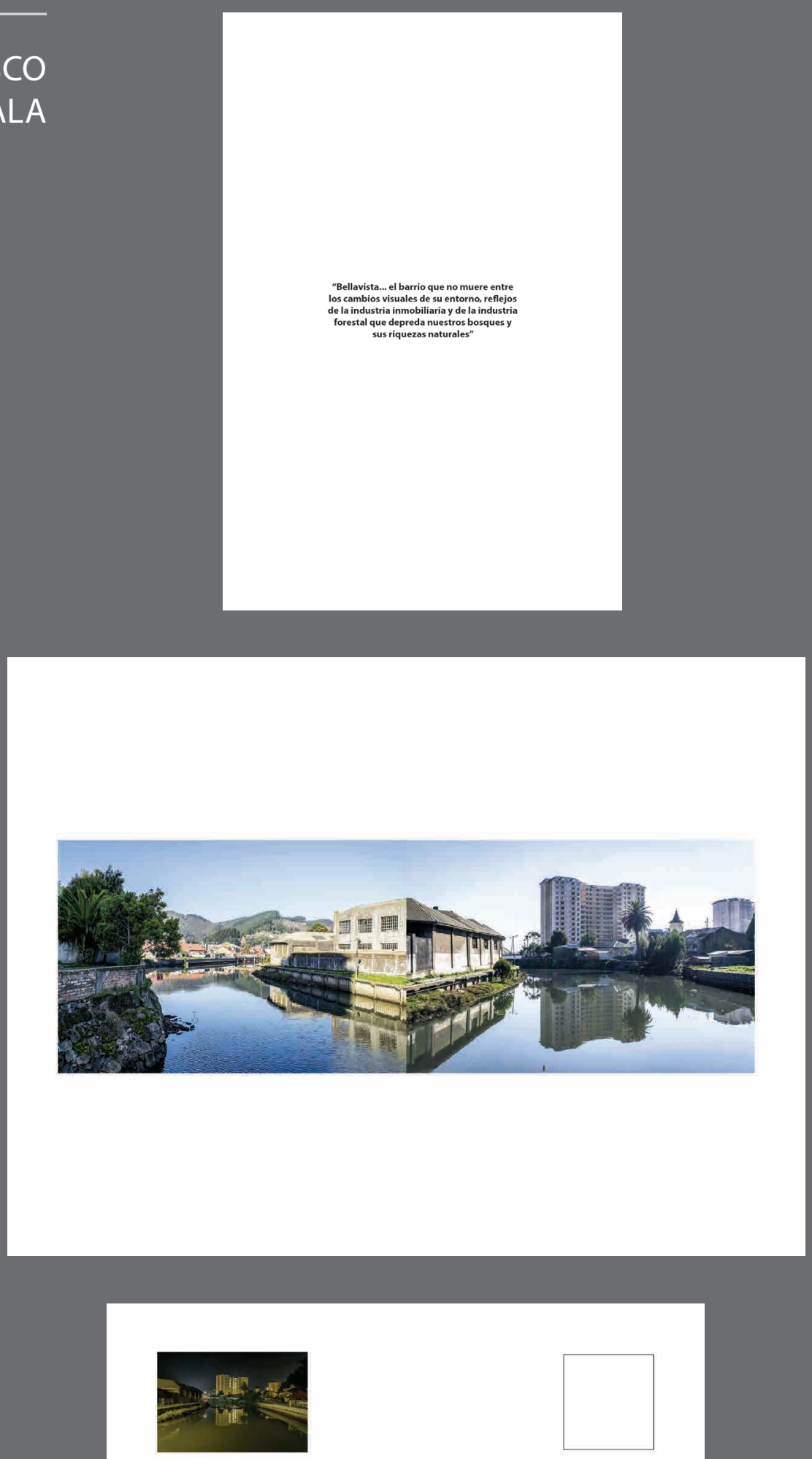

Fotógrafo: Francisco Matamala

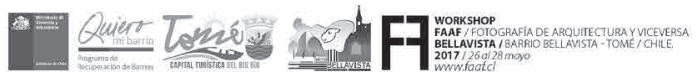




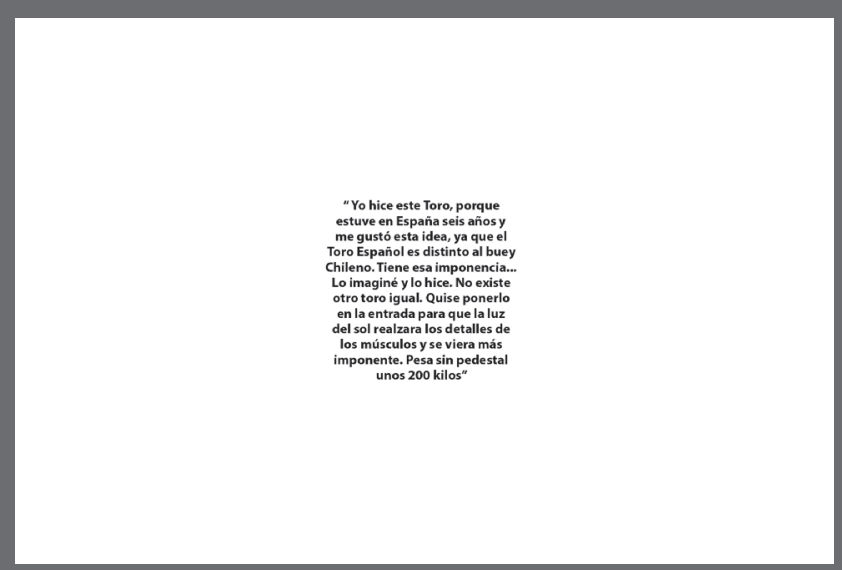

ERIKA

AGUAYO
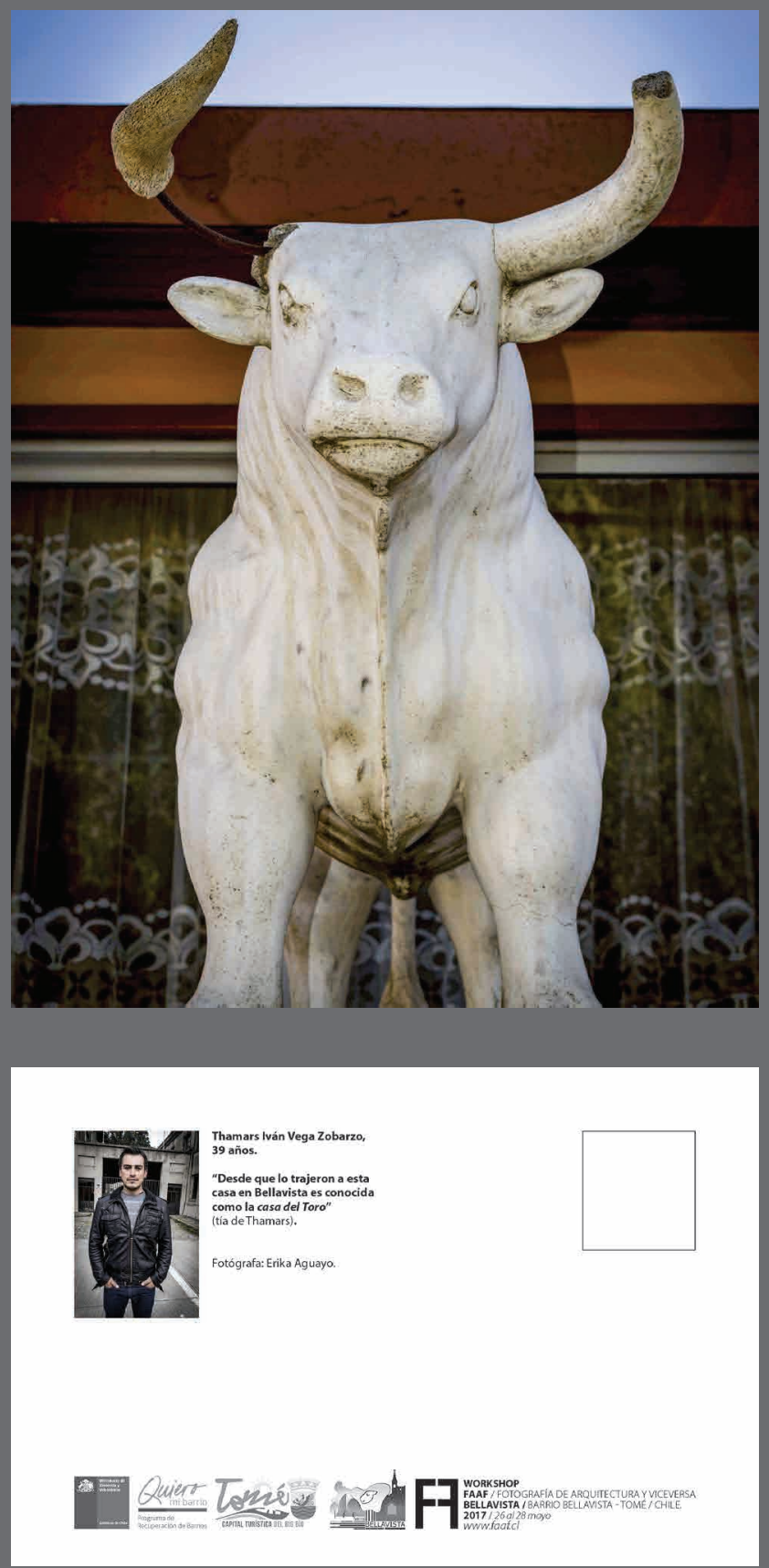
JORGE
MÉNDEZ
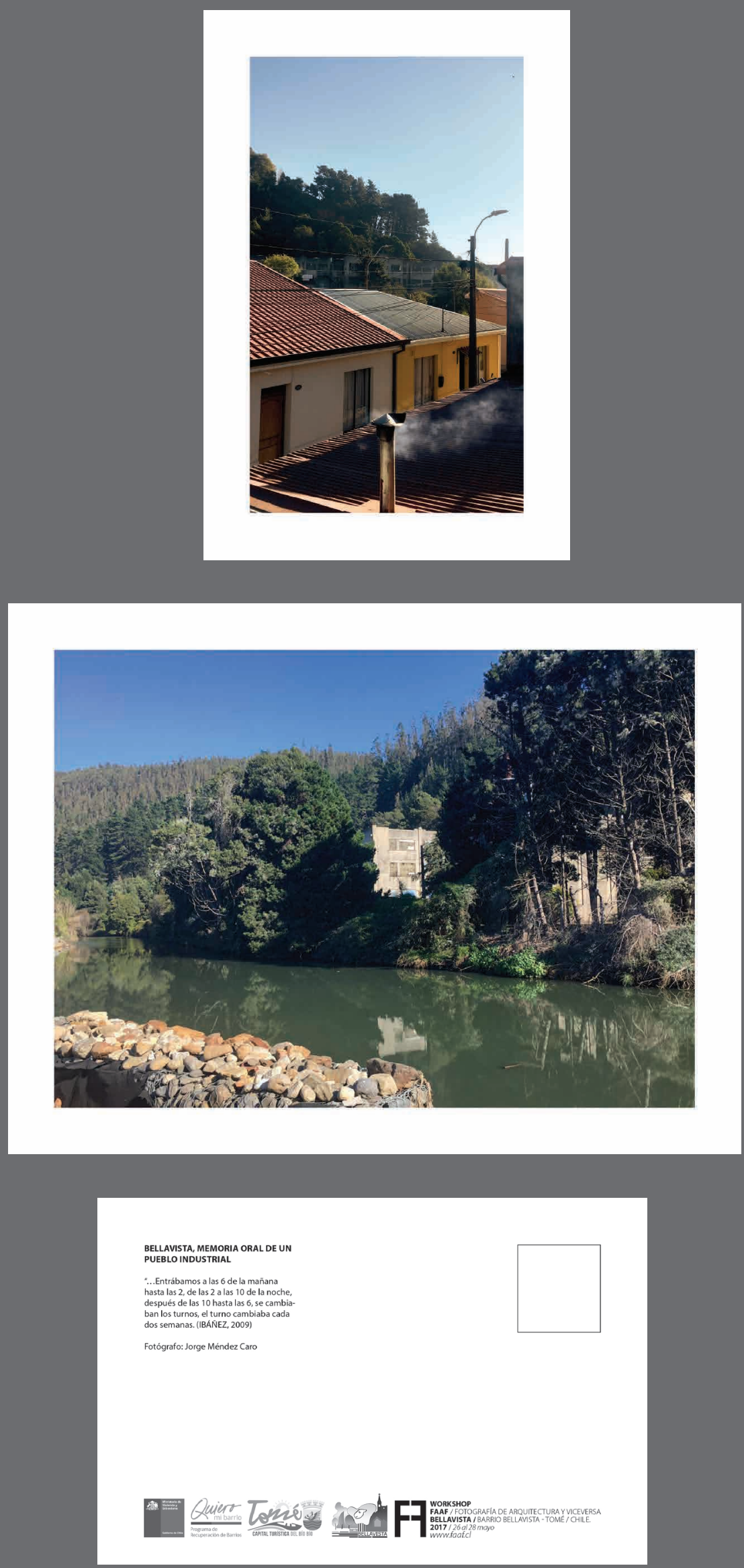


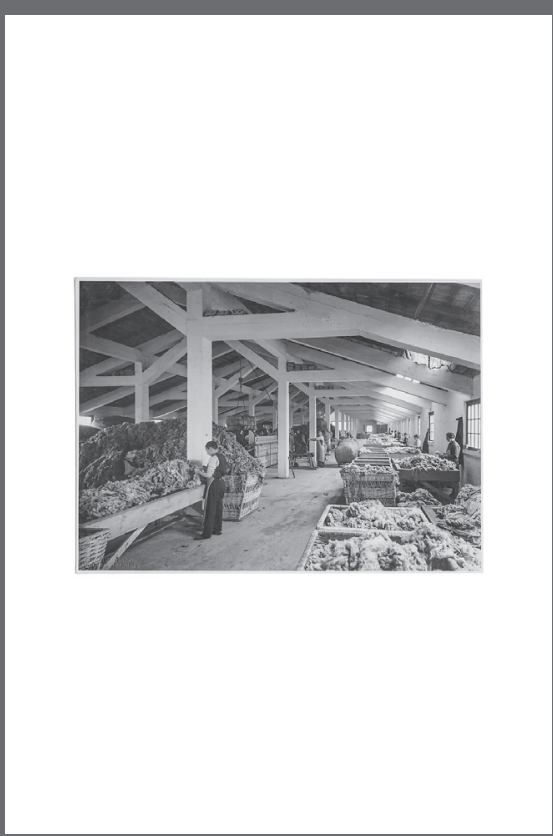

\section{AUTORÍA COLECTIVA}
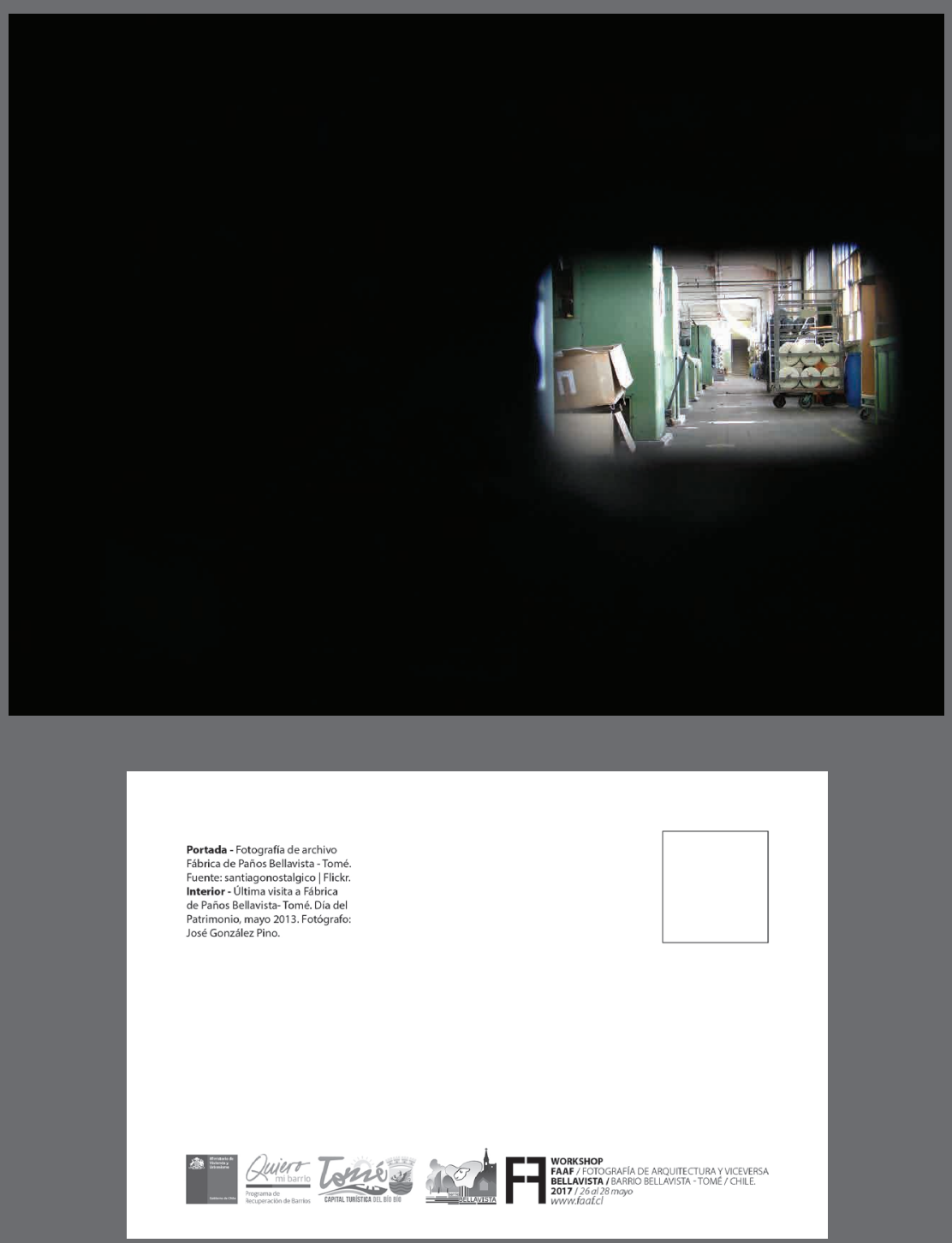
